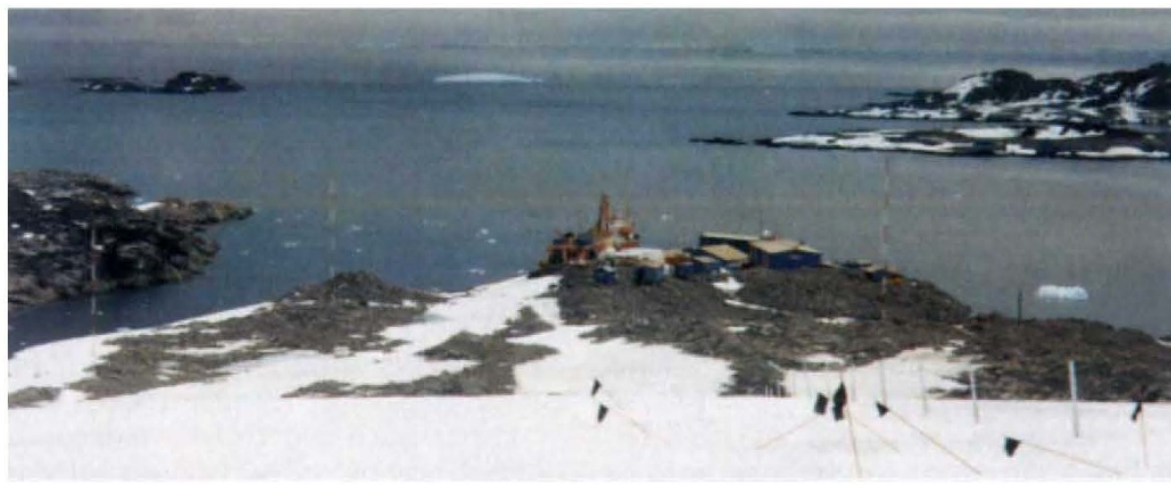

There is little room for crowds at Palmer Station in Antarctica.

\section{NSF hangs out wary welcome sign}

Palmer Station, Antarctica. US ambivalence towards tourism in Antarctica will be sharpened this month by the arrival of a ranger from the US National Parks Service. Her job will be to brief the tourists visiting this research station, the most accessible of the three on the continent.

The National Science Foundation (NSF), which manages the US Antarctic programme, is wary of tourists. Officials fear intrusion on scientific work and violations of the 31year-old Antarctic Treaty, which technically prohibits even encounters with penguins that cause them to run away. But it is also anxious that those who do visit should form a good impression of Antarctica, whence the arrangement that the parks service will supply an "interpretative guide" for the current (Antarctic) summer season.

A dozen ships from various countries will carry 5,600 tourists this season to the west coast of the Antarctic Peninsula to admire its magnificent scenery. But only 1,200 will be allowed to visit Palmer, as passengers on the 12 cruises arranged by the four tour operators with which NSF has made prior arrangements. Their visits will be compressed into six weeks this month and next to avoid disruption to the many research projects that begin a new season in November and December. Until this year, either NSF personnel or employees from a US company hired by NSF to provide support services handled

\section{all dealings with tourists.}

Even so, visitors do not get a guided tour of Palmer but must satisfy their curiosity during an hour-long spell ashore to buy souvenirs at a portable gift shop and enjoy light refreshments in the dining hall. There they may rub shoulders with researchers, who appear at least as interesting to the tourists as the indigenous life-forms. A US tour operator says that the visitors most want to know "what it's like to live and work in Antarctica". Most scientists take these questions in their stride, believing that an educated public will help to preserve Antarctica as a research base.

Palmer's first ranger will be Maureen Loughlin, 36, a wildlife veterinarian with 14 years' service in several national parks. She says that her first task is to "see what works best for visitors"; upon returning to the United States she will develop whatever programmes, exhibits and publications are needed.

But her success may create more problems than it solves. NSF may then face pressure to make the position permanent, which would give an agency that does not have science as its chief mission a role in handling Antarctic affairs. Although it is unlikely that this season's pilot project will open the flood-gates to tourism, it suggests that the "Scientists Only" sign hung over the continent for so many years may not remain forever.

Jeffrey Mervis

\title{
US biotechnology groups merge
}

Washington. The US biotechnology industry has decided to speak with one voice on policy issues. This week, the Association for Biotechnology Companies (ABC) and the Industrial Biotechnology Association (IBA) announced plans to form the Biotechnology Industry Organization, bringing together IBA's 150 member companies with the 340 member firms of $\mathrm{ABC}$. The new association will include more than 300 US biotechnology companies and represent more than 90 per cent of the industry's $\$ 5.9$ billion a year in product sales.
The two organizations have not always seen eye to eye. ABC and IBA took opposing positions over legislative efforts to trim the marketing exclusivity provisions of the Orphan Drug Act. ABC historically has represented smaller biotechnology companies.

In their first joint activity, the two associations asked President-elect Bill Clinton to support measures to stimulate long-term capital formation, strengthen process patent protection and allow the US Food and Drug Administration to collect user fees from companies.
Diane Gershon

\section{NEWS IN BRIEF}

Washington. Witnesses testifying before this year's science subcommittee in the US House of Representatives should expect to spend a good deal of time explaining themselves: only 6 of the 16 members of the subcommittee, whose members were chosen last week, have previously served in Congress, providing vivid evidence of the desire for change that voters expressed last autumn. The subcommittee itself has shrunk from 20 members, with a new subcommittee on technology, environment and aviation attracting the maximum allowable number, 33 . US Representative George Brown (DemocratCalifornia) remains chairman of the parent Science, Space and Technology Committee.

Ron Brown, the choice of President elect Bill Clinton to be secretary of the Commerce Department, appears ready to give greater attention to environmental issues than his predecessors, who traditionally have focused on trade policy. in both oral testimony last week at his confirmation hearing before the US Senate and in written answers to questions, Brown talked about the significant role of the National Oceanic and Atmospheric Administration (NOAA) in monitoring the environment. But his plea for money to modernize the agency's fleet of ships reflects a favourite theme of the new administration: the investment will not only strengthen science, but it also will provide jobs for the US ship-building industry. Brown also strongly supported Clinton's campaign pledge to create more manufacturing technology centres as part of a more ambitious technology initiative within the Commerce Department. But he was careful to remind Congress that such programmes have yet to be drawn up.

Russia is now officially on board as a collaborator for the Superconducting Super Collider (SSC) being built in Texas after US Energy Secretary James Watkins last week signed an agreement between the two governments in the presence of Russian ambassador Vladimir Lukin. The US government regards the contracts with two Russian institutes to help design and build conventional magnets for two of the SSC's five accelerators (the lowenergy and medium-energy boosters that will speed up opposing streams of protons on their way to the main ring, where superconducting magnets will help them reach energies of $20 \mathrm{GeV}$ ) as a way to lower the cost of the $\$ 8.5$-billion accelerator to US taxpayers. Roy Schwitters, director of the SSC laboratory, also points to the special talents of the Budker Institute for Nuclear Physics in Novosibirsk in designing and producing such magnets. The agreement will reduce by half the estimated $\$ 200$-million cost of the magnets.
Jeffrey Mervis 